\title{
Education
}

\section{International Research Interdisciplinary School - May 8-13, 2017, Zhovkva, Lviv, Ukraine}

Mykhaylo Sorokivskyy ${ }^{1}{ }^{2}$, Uliana Pidvalna $^{2}$, lana Andreieva ${ }^{3}$, Ljuba Bacharova $^{4}$

${ }^{1}$ Lviv Regional Cardiology Center, Ukraine

2 Danylo Halytsky Lviv National Medical University, Lviv, Ukraine

3 State Institution "Zaporizhia Medical Academy of Post-Graduate Education Ministry of Health of Ukraine", Zaporizhzhia, Ukraine

${ }^{4}$ International Laser Center, Bratislava, Slovak Republic

In the city of Zhovkva, near Lviv, on May 8-13, 2017, the 20th anniversary International Research Interdisciplinary School (IRIS) for young scientists working in the field of biomedical sciences was held for the first time in Ukraine. The program of this school is based on the Research Workshop developed at Duke University, USA. The initiative for the IRIS was started by the American Journal of Electrocardiology in 2006 and supported by a number of European national and international journals. The main purpose of the school was to develop the ability of its participants to plan and conduct scientific projects in biomedical disciplines.

The international faculty of school was represented by: Ljuba Bacharova, Slovakia, Eric Eisenstein, USA, Katarzyna Piotrowicz, Poland, Mykhaylo Sorokivskyy, Ukraine and observer: Jacqueline Hengl, Austria

There were 20 participants from Ukraine, Slovakia, Lithuania and Denmark. During workshops participants prepared 4 training projects:

Group Evergreen: The effect of the Chamomile extract on the experimental bacterial pneumonia - Kristina Baseviciene (Lithhania), Bacova Maria (Slovakia), Pavol Mikolka (Slovakia), Jaroslav Oryshchyn (Ukraine), Sofiya Vynnytska (Ukraine).

Group HAMAK: The impact of smart phone usage duration on cognitive function in middle age population

- Andrius Alisauskas (Lithuania), Alice Kusnírová (Slovakia), Jana Andreeva (Ukraine), Viktoria Mykhaylova (Ukraine), Liuba Hasiuk (Ukraine).

Group C-BE: The effect of tryptophan rich diet vs. supplement on serotonin levels in patients with post ATB depression - Haroldas Razvadauskas (Lithuania), Agnesa Csanova (Slovakia), Uliana Dmyterko (Ukraine), Glib Royko (Ukraine), Khrystyna Kaminska (Ukraine).
Group The Eye of the Tiger: The impact of melatonin supplementation on the insulin sensitivity of prediabetic medical staff who are working nightshifts Ruta Zakareviciute (Lithuania), Victoria Lory (Slovakia), Jakob Solgaard Jensen (Denmark), Uliana Pidvalna (Ukraine), Anastasija Oryshchyn (Ukraine).

The organizers and participants of IRIS share their thoughts and impressions about the school:

Mykhaylo Sorokivskyy (member of faculty and organizer of IRIS in Ukraine): 20 participants from European countries such as Slovakia, Lithuania, Denmark and Ukraine took part in the work of the school. The general concept lies in the fact that young scientists need to develop gradually a project of scientific research within four working days. Their work is monitored by experienced mentors with considerable experience in research and science, helping to correct deficiencies and make these scientific projects as realistic as possible. The intensive work schedule was complemented by a vivid social program, which included an acquaintance with the historical monuments of Zhovkva and Lviv and, even, small sport competitions.

Uliana Pidvalna (participant). How to do your own research study correctly? How to be confident if all according the rules? What are the most common mistakes? For a long time most of us were looking for an answer to these questions. Frankly speaking, we were aware of some tips and tricks but we all felt that we needed more to gain confidence. Every time when we were desperately struggling with doubts what and how to write to make no mistakes and meet the regulations. We wanted to get an expert who could guide us through the labyrinth of correctly doing research projects. Finally, we found it.

Address for Correspondence: Mykhaylo Sorokivskyy, Lviv Regional Cardiology Center, Lviv, Ukraine.

Email: sorokivskyy@gmail.com

Received: 1.10.2017 Accepted 2.10.2017

Copyright@ 2017 Heart Vessels and Transplantation 
lana Andreieva (participant). From the first day in IRIS we faced with the necessity to collaborate with people from different countries with different backgrounds who work in different biomedical areas and whom we didn't know before that. One of the most significant and inalienable practical skill for every researcher is good communication skills. A scientist has to exchange experience and his results, write articles and proposal, communicate with a variety of audiences and educate others. Thus to become a successful scientist you have to be an effective communicator. During last decade, science has become more interdisciplinary and the ability to communicate more effectively across disciplines fosters collaboration and innovation.

Mykhaylo Sorokivskyy. The most important point at the beginning of the work of each group was the formulation of the hypothesis of the whole study to be carried out. The hypothesis must be meaningful, concrete, expressed in one sentence. It should be formulated on the basis of a number of preliminary data, due to which at this stage the study looks plausible. The main task of scientific research is to either confirm the hypothesis of the data of their own research, or deny it. Then we had to pick up an informative and understandable name for the whole study, which could be the title of the future publication.

lana Andreieva. Every participant has to conduct a presentation of any stage of the project and take part in the final presentation. This one trained our skill in preparation, improved skills in argumentation, negotiation and critical appraisal and helped to overcome some fear of public speaking. Furthermore, all presentations were discussed in a repetitive way not only by mentors but also by participants. It also helps to involve all participants in profound efficient discussion and get constructive feedback. During every workshop, we learned to listen to remarks, accepting criticism and ask for help. For some participants, it seemed a little bit frustrated but when you see results of your work, you realize that it is the best way to find the best decisions and mistakes that could become obstacles in future.

Uliana Pidvalna. What have we achieved? It was really important to us to learn the way how to focus on the main purpose, do not lose important details and do not overload research with unnecessary points at the same time. We have realized that proper hypothesis could facilitate all stages of our work: conduction of experiment, data gathering, processing and preparing manuscript as result of our work. Another important point was group-working experience. Sometimes it was really hard to take into account another point of view and to listen to the opinion of other members of your team and faculties, especially when you fully immersed in a research setting.

Mykhaylo Sorokivskyy. The language of communication at the International Research Interdisciplinary School is English, which was native to none of the participants. Thus, besides the intense work in the scientific circle, the participants feel a certain "linguistic" load. Stay within four working days in the English-speaking environment, both during work and rest, is another extremely important positive aspect of the science school, especially for participants from Eastern Europe.

Uliana Pidvalna. IRIS. It is not only flower, not only part of the vascular tunic of the eyeball, ancient Greek Goddess of the Rainbow, asteroid etc, but also International Research Interdisciplinary School, which is a great possibility to be a little part of such a great scientific family.

Peer-review: Internal

Conflict of interest: None to declare

Authorship: M.S., U.P., I.A., L.B. equally contributed to preparation of report.

Acknowledgement and funding: None to declare. 
Heart Vessels and Transplantation 2017; 1: doi 10.24969/hvt.2017.28
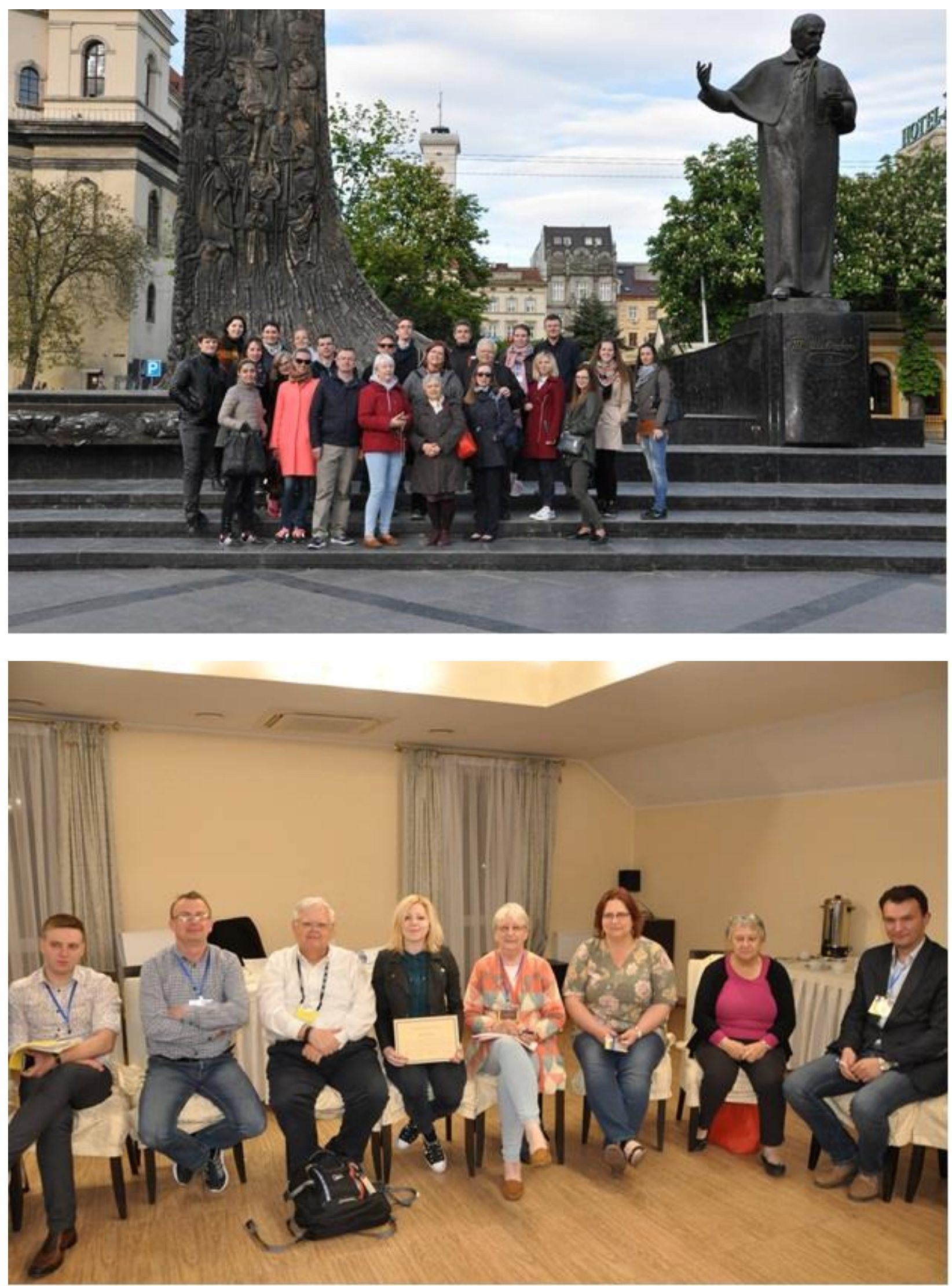

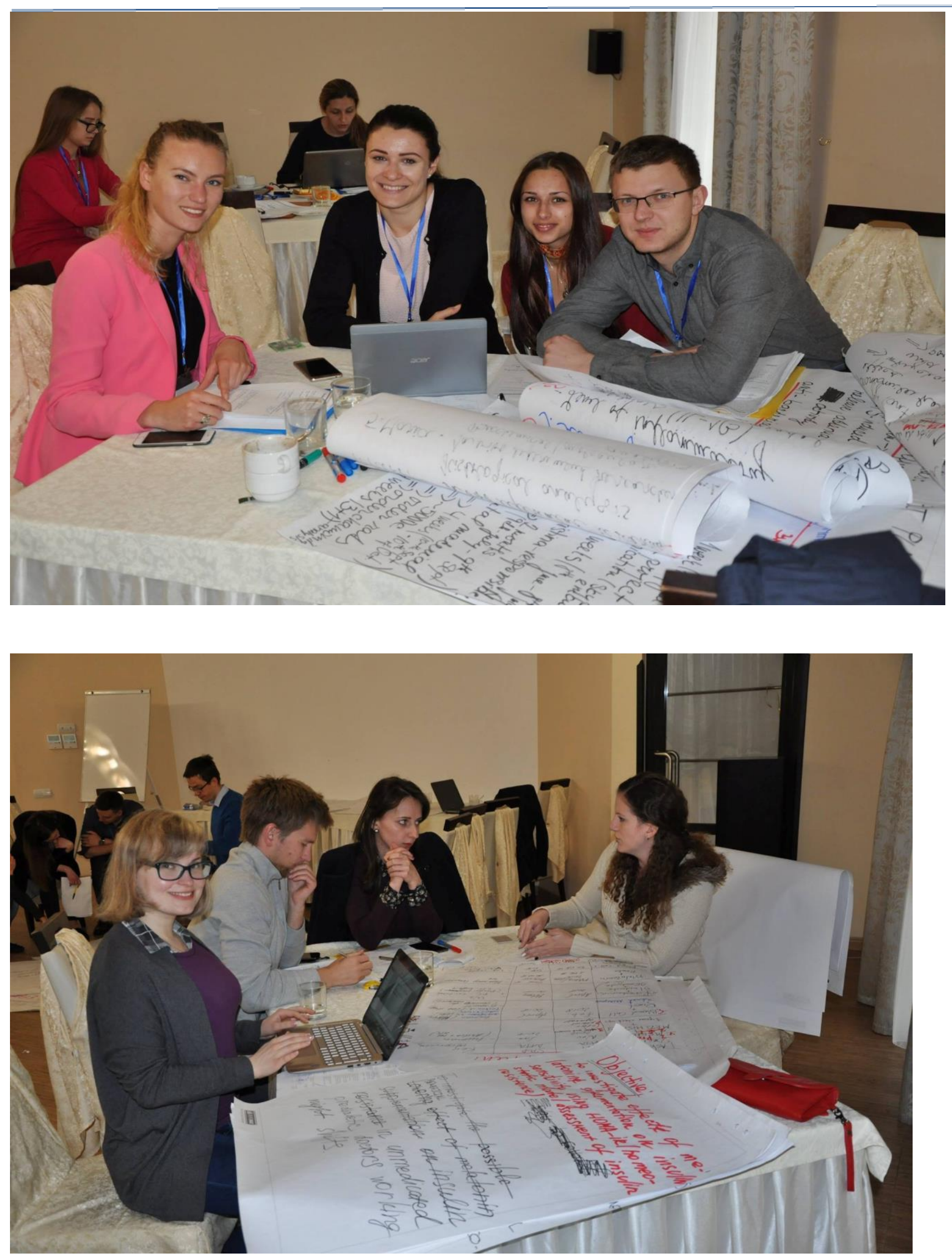
Heart Vessels and Transplantation 2017; 1: doi 10.24969/hvt.2017.28

Research education

Sorokivskyy et al.

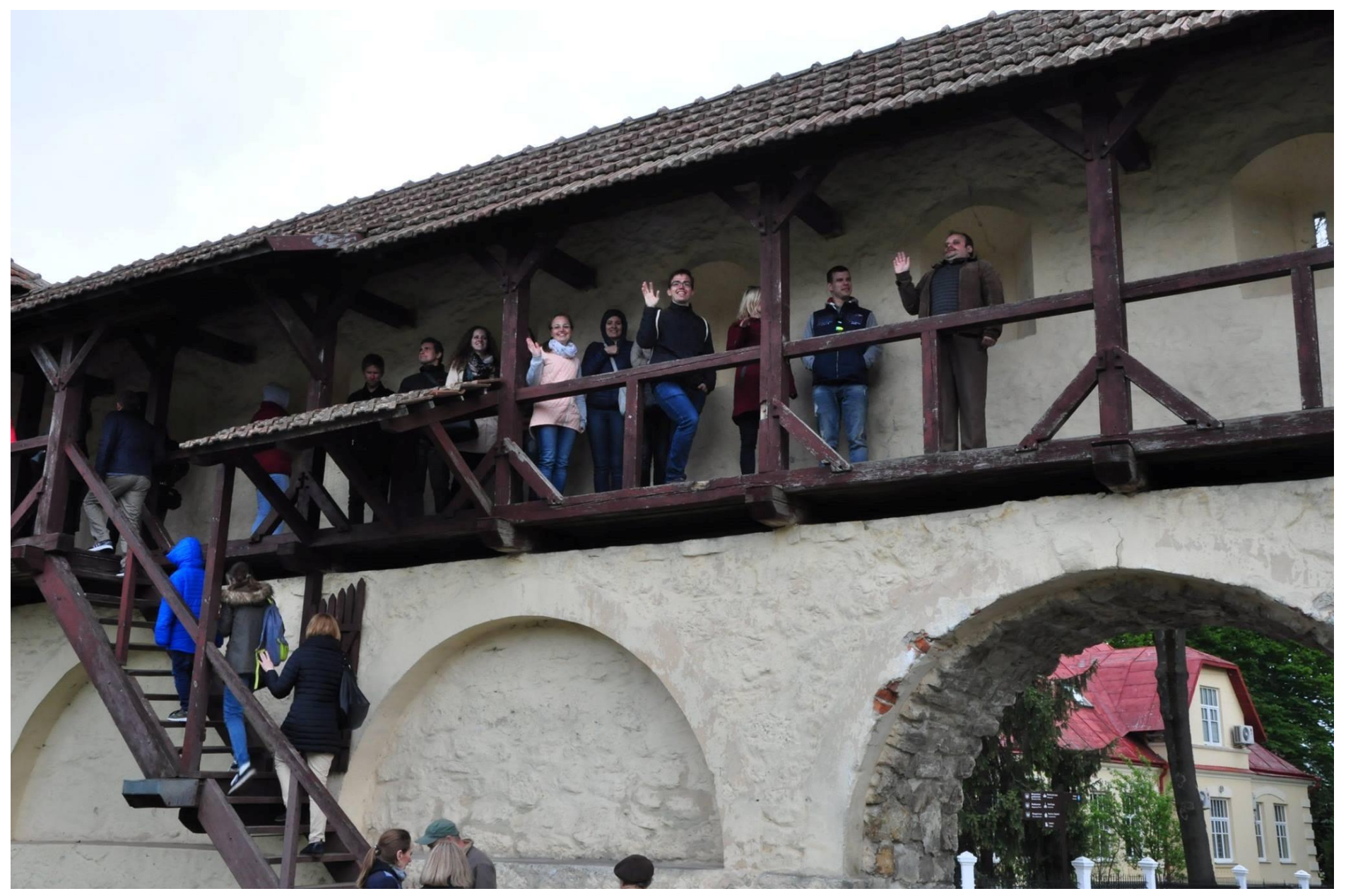

Some pictures from International Research Interdisciplinary School. 